Www.jmscr.igmpublication.org Impact Factor 5.84

Index Copernicus Value: 83.27

ISSN (e)-2347-176x ISSN (p) 2455-0450

crossref DOI: https://dx.doi.org/10.18535/jmscr/v5i7.97

Journal Of Medical Science And Clinical Research

\title{
The effect of Allium Sativum (Garlic) on Pregnancy, Fetal Weights, and Some Hematological Parameters in Albino Rats
}

Authors

Chidiebere .B. Ene ${ }^{1}$, Chukwunonso .A.Oguonu ${ }^{2}$ Paschal.U.Chime ${ }^{3}$, Celestine. O.Ani ${ }^{4}$, Matthew. J.Olasunkanmi ${ }^{5}$, Francis U. Agu ${ }^{6}$, Etim. ${ }^{7}$.Daniel. C.Nwachukwu ${ }^{8}$ Anyaehie. B.Ugochukwu'

${ }^{1}$ Department of Chemical Pathology, College of Medicine University of Nigeria, Enugu Campus, Nigeria 3,6,7,9 Dept of Physiology, Faculty of Basic Medical Sciences, University of Nigeria, Enugu Campus Nigeria.

${ }^{2}$ Departments of Pharmacology and Therapeutics, College of Health Sciences, Benue State University

Makurdi, Nigeria,

${ }^{4}$ Department of Medical Biochemistry, College of Medicine, University of Nigeria,Enugu Campus Nigeria

${ }^{5}$ Department of Anatomy/Physiology, College of Health Science \& Technology Idah, Kogi State Nigeria

Correspondence Author

*Celestine .O.Ani

Email: anicelestine2006@gmail.com; Phone:+2348034607689

\begin{abstract}
The amount of weight gained during pregnancy can affect the immediate and future health of a woman and her infant and could lead to complication such as hypertension in pregnancy. However, some studies has proposed some benefits of some of the antioxidants found in garlic in reducing the occurrence of hypertension in pregnancy, heart attack etc but there is paucity of information on the effect of garlic in pregnancy, fetal weights/sizes and hematological parameters and these suffixed our investigation of the effects of garlic on these parameters. The effect of Allium sativium (garlic) on pregnancy, fetal weights and some hematological parameters were investigated in albino rats of wistar strain. The animals were divided into four (4) groups A, $B, C$ and $D$ of ten $(n=10)$ female rats each. Group A (control) was fed with normal rats chow and water ad libitium. Group B were induced to pregnancy and treated with aqueous AS extract, Group $C(n=10)$ pregnant and received $A S$ extract, Group $D(n=10)$ non pregnant and received AS extract. Each of the rats baseline parameters were determined prior to induction of pregnancy followed by weekly assessment of the parameters. There were significant increase in the body weights $(C>A>B>D)$ respectively. They were compared statistically with $P<0.05$ considered statistically difference. There was a significant difference $(P<0.05)$ in the body weights of groups B, C and D compared with control group A. In the fasting blood glucose level (FBGL), there was a decrease in group $B$ while group $C$ did not show any significant increase/decrease and groups $B$, $C$ and $D$ were compared with group $A$ and there was no significant difference $(P>0.05)$ among the groups. There was a significant increase in the $R B C$.It also, showed a statistical significant difference $(P<0.05)$ between group $A$ and $C$ on the day 14 and 21 respectively. The WBC of all the groups showed a significant increase throughout the experimental period and there were significant difference $(P<0.05)$ between groups $B$, $C$ and D compared with $A$ on day 14 and 21, respectively. The HBC of groups $A$ and D increased significantly while group $B$ did not show any significant increaseldecreased and $C$ decreased respectively. There were
\end{abstract}


significant differences $(P<0.05)$ between groups $C$ and $D$ compared with $A$ on day 14 and 21 respectively. There was significant increase in the PCV of groups $A$ and $D$ while groups $B$ and $C$ decreased significantly. There were significant differences between groups $B, C$ and D compared to group $A$ on day 14 and 21 , respectively. Platelet counts decreased significantly in all the groups and there were no significant differences $(P>0.05)$ among the groups compared with A. Therefore, these results suggest that the consumption of garlic during pregnancy has a beneficial effect in the reduction of maternal/fetal weights and litter sizes and maintenance of the blood parameters including FBGL.

Keywords: Litter weights/sizes, blood glucose, hematological parameters.

\section{INTRODUCTION}

Excessive weight gain during pregnancy has shown to increase blood volume, cardiac output and blood pressure during pregnancy. They showed almost a 6-fold rise of induced hypertension compared with women who had adequate gestational weight ${ }^{[1]}$. The populations demographics of women who become pregnant have changed dramatically over the past decade, more women are overweight or obese at conception. Evidence supports associations between excessive gestational weight gain and increased birth weight and post-partum weight retention but also between inadequate weight gain and decreased birth weight ${ }^{[2]}$. Studies have shown that obesity and excessive weight gain during pregnancy had 1.78 times the odd of caesarean section delivery as compared with normal body mass index and adequate weight gain in pregnancy ${ }^{[3]}$. Excessive weight gain (obesity) is thought to trigger changes in the body metabolism. These changes cause fat tissues (adipose tissue) to release fat molecules into the blood which can affect insulin responsive cells and lead to reduced insulin sensitivity which could cause type 2 diabetes. An increase in overall fatness preferentially of visceral as well as ectopic fats depots is specifically associated with insulin resistance and the accumulation of intramyocelluar lipids may be due to reduced lipid oxidation. It is a well-known fact that excessive weight gain is associated with diabetes, hypertension and hyperlipidemia which are major risk factors for artery disease because of increase blood volume, increased cardiac output increased accumulation of fats in adipose tissues and decreased sensitivity of insulin to glucose.
Avoiding excessive weight gain before and during pregnancy help to reduce these ${ }^{[4]}$. Obesity which is an oxidative stressed condition worsens the complications and the uses of antioxidant found in garlic are protective against this free radical damage in the body. Antioxidant properties of Allium sativum (garlic) compounds represent the four main chemical classes, alliin, allyl cysteine, allyl disulphide and allicin exhibit different pattern of antioxidant activities as protective compounds against free radical damage ${ }^{[5]}$. Therefore, there is paucity of information on the effect of garlic in pregnancy, fetal weights/sizes and hematological parameters and these suffixed our investigation of the effects of garlic on these parameters.

\section{MATERIALS AND METHODS}

\section{Plant collection and identification}

The cloves of A. sativium were purchased from a local market in Enugu, South-Eastern Nigeria and were identified and authenticated at the Herbarium unit of the Department of Plant Science and Biotechnology, Faculty of Biological Sciences of the University of Nigeria Nsukka by a taxonomist and a sample of the plant was kept at their herbarium unit with voucher number UNN/2016/1126C.

\section{Preparation of the extract}

The A. sativium bulbs were peeled and washed with distilled water to reduce the microbial loads that could be found on the surface of the bulbs and were air dried under a shed. $500 \mathrm{~g}$ of the weighed garlic bulbs were crushed and blended with an electric blender by Thermocool Product Ltd. The resultants were squeezed and sieved using a What 
man clean dry piece of cloth.25 $\mathrm{g}$ of the powered A. sativium was weighed and mixed in approximately $100 \mathrm{ml}$ of distilled water and the mixture was allowed to stand for $48 \mathrm{~h}$ after which it was filtered using Whatman filter paper of size (N0. 41). The filtrate was collected in a beaker and stored in a refrigerator at about $3^{\circ} \mathrm{C}$ till ready for use in which oral route of administration was used using a stainless oral cannula for rats and the using the formula stated as follows:

\section{Dose $(\mathrm{mg} / \mathrm{kg}) \times$ weight of the rats $(\mathrm{kg})$ \\ $\mathrm{Vol}=$}

Stock concentration $(\mathrm{mg} / \mathrm{ml})$

\section{Phytochemical screening}

This study investigated the qualitative and quantitative analysis of the major bioactive constituents of A. sativium (garlic) in its aqueous nature. The phytochemical tests were conducted using standard method of ${ }^{[6]}$ for standard analysis. The result of the phytochemical screening showed the presence of flavonoids, alkaloids, saponin, tannin and cardiac glycosides. Quantitative analysis showed the highest yield of tannins (2.5 $\mathrm{g} / 100 \mathrm{~g})$ and lowest yield of flavonoids (0.05 $\mathrm{g} / 100 \mathrm{~g}$ ). Saponin was $0.24 \mathrm{~g} / 100 \mathrm{~g}$ and cardiac glycoside $(1.88 \mathrm{~g} / 100 \mathrm{~g})$.

\section{Determination of the weights}

The body weights of the experimental animals were determined prior to the commencement of the research in order to determine their baseline values in which the top loading digital weighing balance by Havard apparatus was turned $\mathrm{ON}$ and allowed to stabilize. A cylindrical transparent glass rats restrainer was placed on the balance and weighed and the weight tarred to zero mark before introducing the rats individually and their weights were recorded in gram $(\mathrm{g})$

\section{Determination of liter sizes}

A small piece of tailors thread was used to measure the liter sizes in which the thread was used to measure the height of the liter from the base of the caudal region to the forehead and the length measured on a meter rule to ascertain the height in meter. Moreover, the thread was also measured round their abdominal region to determine the circumference of their abdomen and recorded in meters.

\section{Determination of haematological parameters}

The Automated Hematological Analyzer was used to analyze the hematological parameters like packed cell volume (PCV), white blood cell count (WBC) red blood cell count (RBC), hemoglobin concentration (HB) and platelet count (PCT). The analyses were carried out based on standard methods.

\section{Experimental animals}

A total of forty-eight in breed wistar rats of age between 10 and 12 weeks of weight ranging from 120 to $200 \mathrm{~g}$ were used for this study. They were procured from the Animal House Unit of the Department of Pharmacology/Toxicology of the Faculty of Pharmaceutical Sciences of the University of Nigeria, Nsukka and transported to Animal House Unit of the Department of Pharmacology/Therapeutics of the College of Health Sciences, Benue State University, Makurdi, where the research was conducted after 14 days of acclimatization under $12 \mathrm{~h}$ dark/light cycle. The rats were housed in cages and maintained under standard environmental conditions of about $27^{\circ} \mathrm{C}$ and were provided with clean water and commercial rats feed (Vital feeds ltd, Jos Plateau State Nigeria) ad libitum. The animals were handled according to the protocols approved by the Research Ethics Committee of the University of Nigeria Teaching Hospital Enugu.

\section{Acute toxicity test}

The acute toxicity test was performed according to the method of ${ }^{[7]}$ which involves two phases (1 and 2). Phase 1 required 9 non pregnant female rats divided into three groups each. Each group of the animals was administered different dosages 
$(10,100$ and $1000 \mathrm{mg} / \mathrm{kg})$ of the garlic extract and placed under observation for $24 \mathrm{~h}$ to monitor their behavior as well as mortality. While Phase 2 involves the use of 3 non pregnant female wistar rats distributed into three groups of one animal each. The animals were administered higher doses $(1600,2900$ and $5000 \mathrm{mg} / \mathrm{kg})$ and then observed for $24 \mathrm{~h}$ for mortality or signs of toxicity. The $\mathrm{LD}_{50}$ was calculated using the formula by ${ }^{[7]}$ :

LD50 = square root $\left(\mathrm{D}_{\mathrm{O}} \times \mathrm{D}_{100}\right)$

$\mathrm{D}_{\mathrm{O}}=$ Highest dose that gave no mortality; $\mathrm{D}_{100}=$ Lowest dose that produced mortality.

\section{Induction of pregnancy in rats}

The estrous cycle of the female rats were monitored and males of proven fertility were introduced into their cages in the ratio of one male to five females (1:5) and allowed for mating to occur. Mating in the females were confirmed from a vaginal smear in which a clean cotton swabs were inserted into the vagina of the female rats and samples of deposit of semen were collected and observed for grey or protein coagulate in normal saline solution $(0.9 \% \mathrm{NaCl})$ and a clean glass slide was provided and a drop of the semen solution was collected using a pipette and dropped on the slide and covered with a clean cover slip and mounted on a microscope and viewed for the presence of dead spermatozoan. The presence of dead spermatozoan was confirmed ${ }^{[9]}$. Fertility and conception in the female wistar rats were confirmed from by the traditional methods such as; aggressiveness of the female rats after mating, copulatory plugs in their vagina which is a sign that it has been mated and avoidance of other males from mounting her, slight daily increase in their body weight more than non-pregnant ones, cessation of estrus cycle, hair loss around the nipple mostly in the last week of parturition and enlarged lower abdomen and more interest in food intake.

\section{Experimental Design}

A total of forty-eight healthy rats after acclimatization were used. The rats comprised of forty (40) females and eight (8) males. They were divided into four groups comprising of the follows:

Group A $(\mathrm{n}=10)$ : No pregnancy and received no garlic (control):

Group B $(n=10)$ : Pregnancy+ garlic

Group C $(n=10)$ : Pregnancy- garlic

Group D $(\mathbf{n}=\mathbf{1 0})$ : No pregnancy + garlic

\section{Statistical analysis}

The collected data were presented as mean \pm standard deviation $(\mathrm{X}+\mathrm{SD})$ and were analyzed using the statistical package for social sciences (SPSS) computerized software version 21). The data generated were analyzed using one-way analysis of variance (ANOVA) with post-hoc (Turkey) test for comparing their means. A probability $\mathrm{P}<0.05$ was considered statistically significant.

\section{RESULTS}

Table 1 showed the result of the qualitative and quantitative analysis of the major bioactive constituents of SA (garlic) in its aqueous nature. The phytochemical screenings were conducted with strict adherence with the standard method of analysis. This result shows the presence of flavonoids, alkaloids saponin, tannin, carbohydrate, reducing sugar and alkaloid. The qualitative analysis showed the highest yield of tannin $(2.52$ $\mathrm{g} / 100 \mathrm{~g})$ and lowest yield of flavonoids (0.05 $\mathrm{g} / 100 \mathrm{~g}$ ) etc.

Table 2 shows the effect of $A$. sativium on body weight of all treatment groups. From the table they observed that there was an increase in body weights of all the groups A, B, C, D from day zero to day 21, but the weight of group A (control) was compared statistically using their mean + standard derivation (Mean $\pm \mathrm{SD}$ ) and found that there was no significant difference $(\mathrm{P}>0.05)$ in their body weights from the day 7 (week 1) of the treatment with the A. sativium extract till the end of the experimental period (day 21 ).

Table 3 shows the mean body weights/ litter sizes of the post natal litters. Therefore, group B shows 
a significant decrease in the post natal weights of the litters and sizes compared to group C. This shows that garlic caused a significant reduction in body weights of the dam during the experimental periods. The effect was not significant in the post natal litter sizes and there was no significant difference between group $\mathrm{B}$ and $\mathrm{C}$ in the post natal litter sizes and weights.

Table 4 shows the result of the mean + SD of effect of $S A$ extract on the fasting glucose level measured in milligram per deciliter $(\mathrm{mg} / \mathrm{dl})$. There was no significant increase or decrease in the control (group A) as the variation in their fasting blood sugar level fluctuated with a slight decrease on day 14 (week 2). There was a decrease in the fasting blood glucose level of group B. Group C (no garlic + pregnancy) did not show any significant increase or decrease in fasting blood sugar level but group D showed a significant decrease in fasting blood sugar level from $88.60 \pm$ 8.90 to $77.40 \pm 6.3$. All the experimental test groups were compared statistically with the control group A and formed that there were no significant differences $(\mathrm{P}>0.05)$ among all the treatment groups compared with control group A from the onset of the experiment till the end on day 21 (week 3).

Table 5 shows the effect of AS (garlic extract) on the RBC parameter expressed in million per cubic millimeter. Groups A, B and D showed a slight increase on their RBC compared to group A. The treatment groups were compared with control (group A) and the result showed a P-value less than $0.05(\mathrm{P}<0.05)$ and ways considered to have statistically significant difference $(\mathrm{P}<0.05)$ on the day 14 and 21 (week 3 ) of the experimental period .But there was no significant difference $(\mathrm{P}>0.05)$ on days 0 and 14 when compared using one-way ANOVA, multiple comparison show a significant difference $(\mathrm{P}<0.05)$ between grou espectively.p $\mathrm{C}$ compared with group A on day 14 and $21 \mathrm{r}$

Table 6 shows the result of the Mean \pm SD of the effect of A. sativium on haemoglobin concentration of all the rats in the experiment. There were significant increase in the haemoglobin concentration of group A, B and D but non in group $\mathrm{C}$. Group $\mathrm{C}$ decreased from a mean \pm SD of $13.20 \pm 1.05$ to $11.40 \pm 0.34$. Their mean values and standard derivation were compared statistically using one-way ANOVA on the days and found that there were significant difference $(\mathrm{P}<0.05)$. Groups $\mathrm{B}, \mathrm{C}$ and $\mathrm{D}$ were also compared individually using multiple comparison and discovered that group $\mathrm{B}$ and $\mathrm{C}$ were statistically significant $(\mathrm{P}<0.05)$ difference on day 14 and 21 of post treatment period, but there was no significant difference between group $D$ and the control group A ( $P>0.05)$. Table 7 also shows the result of the effect of SA on PCV of the rats. At the endof the experiment (day 21), it was observed that the PCV of the control groups A and D increased significantly. Group A increased from 35. $80 \pm 1.48$ to $40.60 \pm 0.89$ and group $\mathrm{D}$ increased from $36.20 \pm 2.86$ to $42.20 \pm 2.39$ while groups $\mathrm{B}$ and $\mathrm{C}$ decreased in their values respectively Group B with an initial value of $37.00 \pm 2.90$ decreased to $36.20 \pm 1.14$ and group $C$ decreased from $38.80 \pm 2.77$ to $34.00 \pm 1.22$ though their decrease could be negligible. They were compared statistically to certain the level of their significant difference on day 14 and 21 and discovered that there were significant difference $(\mathrm{P}<0.05)$ on day 14 and 21 respectively when compared to the control group A. They were also compared individually with the control group A using post hoc test and found that groups B, C and $\mathrm{D}$ were significantly difference with group $\mathrm{A}$ on day 14 and 21 respectively.

Table 8 stated the mean \pm standard deviation of the weekly platelet count on the effect of SA on pregnant rats. Their platelet values were discovered to have decreased throughout the experimental periods. These decreasing effects was also compared statistically using one-way ANOVA and found that there were no significant differences $(\mathrm{P}>0.05)$ among all the experimental groups compared with A. They were analyzed individually and compared with group A and found that it was only group $\mathrm{D}$ that showed a statistically significant difference $(\mathrm{P}<0.05)$. 
Table 9 shows the result of the mean \pm standard deviation of the total white blood cell count of all the experimental groups. There was a significant increase in the white blood cells of all the groups A, B, C and D. with appreciable values. But that values were compared statistically using one ay ANOVA on the day 7, 14 and 21 and formed that there was a significant difference $(\mathrm{P}<0.05)$ groups on day 14 and 21 compared with the control (group A) but not with day 0 and 7.There were compared individually with group A Group B and $\mathrm{C}$ were statistically different $(\mathrm{P}<0.05)$ compared with group A on Day 21 but there was a significant difference $(\mathrm{P}<0.05)$ between group $\mathrm{D}$ compared with group A on day 14 and 21 respectively.

Table 1. Qualitative and quantitative analysis of garlic

\begin{tabular}{|c|c|c|}
\hline Phytonutrient & Quantity (g/100 g) & Quality \\
\hline Alkaloid & 0.03 & + \\
\hline Tannin & 2.52 & +++ \\
\hline Saponin & 0.24 & ++ \\
\hline Cardiac glycoside & 1.88 & +++ \\
\hline Flavonoids & 0.05 & + \\
\hline Reducing sugar & Nil & - \\
\hline Carbohydrate & 0.07 & + \\
\hline $\begin{array}{cc}\text { Key; } & +++ \\
& ++ \\
& +\end{array}$ & $\begin{array}{l}\text { on } \\
\text { tration } \\
\text { n }\end{array}$ & \\
\hline
\end{tabular}

Table 2. The mean \pm standard deviation pre/post natal materials body weights.

\begin{tabular}{lcccc}
\hline Group & Day 0 & Day 7 & Day 14 & Day 21 \\
\hline A & $130.32 \pm 12.3$ & $142.60 \pm 13.5$ & $152.80 \pm 10.64$ & $161.30 \pm 11.5$ \\
B & $134.18 \pm 12.58$ & $137.20 \pm 12-03$ & $141.60 \pm 11.71$ & $145.90 \pm 11.41$ \\
C & $132.80 \pm 5.39$ & $142.40 \pm 5.46$ & $128.80 \pm 6.57$ & $168.40- \pm 8.96$ \\
D & $141.9 \pm 10.34$ & $135.00 \pm 10.58$ & $127.9 \pm 10.06$ & $115.60 \pm 9.55$ \\
\hline
\end{tabular}

Values were pressed as mean \pm SD: $* \mathrm{P}<0.05$ compared with $\mathrm{A}$.

Table 3. The mean body weights/litter sizes of the offspring after birth.

\begin{tabular}{lcccc}
\hline Groups & Day 0 & Day 7 & Day 14 & Day 21 \\
\hline B & $5.67 / 4.52$ & $6.54 / 4.91$ & $8.20 / 5.01$ & $9.34 / 6.58$ \\
C & $6.82 / 5.10$ & $8.6 / 5.52$ & $8.40 / 5.65$ & $9.52 / 7.22$ \\
\hline
\end{tabular}

Table 4. The mean \pm SD of fasting blood glucose level (mg/dl)

\begin{tabular}{lcccc}
\hline Groups & Day 0 & Day 7 & Day 14 & Day 21 \\
\hline A & $90.20 \pm 34.80$ & $91.00 \pm 32.3$ & $89.80 \pm 33.6$ & $90.80 \pm 31.8$ \\
B & $82.00 \pm 12.70$ & $81.60 \pm 12.8$ & $80.00 \pm 12.40$ & $78.60 \pm 12.4$ \\
C & $94.00 \pm 10.20$ & $94.40 \pm 10.3$ & $92.20 \pm 7.8$ & $94.60 \pm 9.5$ \\
D & $84.60 \pm 8.90$ & $82.20 \pm 8.3$ & $79.80 \pm 7.2$ & $77.40 \pm 6.3$ \\
\hline
\end{tabular}

Values are expressed as Mean \pm SD $* \mathrm{P}<0.05$ compared with $\mathrm{A}$. 
Table 5. Mean \pm SD of the RBC counts for all the experimental groups $\left(\times 10^{6} / \mathrm{mm}^{3}\right)$.

\begin{tabular}{lcccc}
\hline Groups & Day 0 & Day 7 & Day 14 & Day 21 \\
\hline $\mathrm{A}(\mathrm{n}=10)$ & $5.04 . \pm 0.52$ & $5.30 \pm 0.58$ & $5.48 \pm 0.44$ & $5.76 \pm 0.40$ \\
$\mathrm{~B}(\mathrm{n}=10)$ & $6.94 \pm 1.07$ & $7.08 \pm 1.07$ & $7.32 \pm 1.11^{*}$ & $7.56 \pm 1.27^{*}$ \\
$\mathrm{C}(\mathrm{n}=10)$ & $6.56 \pm 0.53$ & $6.76 \pm 0.72$ & $6.70 \pm 1.11^{*}$ & $7.08 \pm 0.76^{*}$ \\
$\mathrm{D}(\mathrm{n}=10)$ & $5.66 \pm 1.12$ & $6.76 \pm 1.31$ & $7.36 \pm 1.27$ & $7.84 \pm 1.22$ \\
\hline $\mathrm{V}$ &
\end{tabular}

Values are expressed as Mean $\pm \mathrm{SD} * \mathrm{P}<0.05$ compared with $\mathrm{A}$.

Table 6. The Mean \pm SD of the haemoglobin concentration $(\mathrm{g} / \mathrm{dl})$

\begin{tabular}{lcccc}
\hline Groups & Day 0 & Day 7 & Day 14 & Day \\
\hline $\mathrm{A}(\mathrm{n}=10)$ & $12.40 \pm 0.65$ & $12.90 \pm 0.65$ & $13.30 \pm 0.45$ & $13.70 \pm 0.5$ \\
$\mathrm{~B}(\mathrm{n}=10)$ & $12.60 \pm 1.14$ & $12.80 \pm 1.27$ & $12.50 \pm 1.00$ & $12.70 \pm 0.82$ \\
$\mathrm{C}(\mathrm{n}=10)$ & $13.20 \pm 1.05$ & $13.20 \pm 0.85$ & $12.00 \pm 0.35^{*}$ & $11.40 \pm \quad 0.34^{*}$ \\
$\mathrm{D}(\mathrm{n}=10)$ & $12.50 \pm 0.61$ & $12.80 \pm 1.05$ & $13.30 \pm 0.88^{*}$ & $13.60 \pm 0.53^{*}$ \\
\hline
\end{tabular}

Values are expressed as mean $\pm \mathrm{SD} * \mathrm{P}<0.05$ compared with $\mathrm{A}$.

Table 7. The mean \pm standard deviation of the weekly packed cell volume (PCV) counts (\%).

\begin{tabular}{lcccc}
\hline Groups & Day 0 & Day 7 & Day 14 & Day 21 \\
\hline A & $35.80 \pm 1.48$ & $36.60 \pm 1.14$ & $38.00 \pm 1.22$ & $40.60 \pm 0.89$ \\
B & $37.00 \pm 2.90$ & $36.80 \pm 3.11$ & $36.20 \pm 1.79^{*}$ & $36.20 \pm 1.14^{*}$ \\
C & $38.80 \pm 2.77$ & $37.60 \pm 2.88$ & $35.60 \pm 1.52^{*}$ & $34.00 \pm 1.22^{*}$ \\
D & $36.20 \pm 2.86$ & $38.20 \pm 2.86$ & $40.00 \pm 2.55^{*}$ & $42.20 \pm 2.39^{*}$ \\
\hline
\end{tabular}

Values are expressed as Mean $\pm \mathrm{SD} * \mathrm{P}<0.05$ compared with $\mathrm{A}$.

Table 8. The mean \pm SD of the weekly platelet counts $\left(\times 10^{9} / \mathrm{L}\right)$.

\begin{tabular}{lcccc}
\hline Groups & Day 0 & Day 7 & Day 14 & Day 21 \\
\hline A & $260.80 \pm 42.68$ & $259.00 \pm 42.13$ & $256.83 \pm 41.04$ & $256.80 \pm 44.99$ \\
B & $278.00 \pm 33.45$ & $270.00 \pm 33.45$ & $264.00 \pm 33.66$ & $238.20 \pm 36.02$ \\
C & $251.00 \pm 47.73$ & $245.20 \pm 47.83$ & $238.20 \pm 46.69$ & $227.80 \pm 48.22$ \\
D & $238.20 \pm 44.52$ & $222.00 \pm 38.17$ & $220.80 \pm 33.90 *$ & $205.80 \pm 34.55^{*}$ \\
\hline
\end{tabular}

Values are expressed as mean $\pm \mathrm{SD} * \mathrm{P}<0.05$ compared with $\mathrm{A}$.

Table 9. Mean \pm standard deviation of the WBC counts for all the experimental groups $\left(\times 10^{3} / \mathrm{ml}\right)$.

\begin{tabular}{lcccc}
\hline Groups & Day 0 & Day 7 & Day 14 & Day 21 \\
\hline $\mathrm{A}(\mathrm{n}=10)$ & $5.96 \pm 0.83$ & $5.90 \pm 0.45$ & $5.96 \pm 0.86$ & $6.12 \pm 0.88$ \\
$\mathrm{~B}(\mathrm{n}=10)$ & $6.94 \pm 1.07$ & $7.08 \pm 1.07$ & $7.32 \pm 1.11^{*}$ & $7.56 \pm 1.27^{*}$ \\
$\mathrm{C}(\mathrm{n}=10)$ & $6.56 \pm 0.53$ & $6.76 \pm 0.72$ & $6.70 \pm 1.11$ & $7.08 \pm 0.76^{*}$ \\
$\mathrm{D}(\mathrm{n}=10)$ & $5.66 \pm 1.12$ & $6.50 \pm 1.31$ & $7.36 \pm 1.27^{*}$ & $7.84 \pm 1.22^{*}$ \\
\hline
\end{tabular}

Values are expressed as mean $\pm \mathrm{SD} * \mathrm{P}<0.05$ compared with $\mathrm{A}$.

\section{DISCUSSION}

This study investigated the effect of SA extract (garlic) on pregnancy, fetal weights and hematological parameters in rats. In this study increase in body weights of all the experimental groups from day zero to end of the experimental period indicated an increase in flood volume and the effect of chronic exposure to normal feeds ad libitum. Their feeding habits were not controlled from the research conducted. The group that received no garlic but was pregnant recorded the highest increase in the body weight and that could 
be as a result of the effect of the increasing size of the fetus as the experimental period progresses. This was followed by the control group (A) and group B (Garlic + pregnancy) respectively. While the least value of group D could be as a result of the effect of garlic on body weight and this work is in agreement with that of Mak-Son ${ }^{[16]}$ This highest value recorded in the pregnant and not treated group could be as a result of non-specific metabolic stimulant in the gonad which is at the height of its activity during pregnancy together with the general increase in the size and weight of the whole reproductive system resulting from the pregnancy. This condition accounts in some measure for the increase in weight of the pregnant animal over the non-pregnant during the same period. According to the journal of nutrition published in November 2011 researcher looked at the effect of garlic and fat storage in mice and discovered that garlic has the potential to reduce body weight due to its capacity to burn body fats. Allyi Isothiosulfate which is a major constituent or components of garlic, inhibits antiinflammatory effects. The beneficial effects of garlic can be attributed to organosulfur compounds including alliciin and its derivatives [10]. The slight decreasing effect on some of the groups treated with the garlic extract could be as a result of minute quantity of flavonoid present which acts as an antioxidant present in garlic. The researchers concluded that garlic could play a role in weight management causing the animal to take in fewer calories. Moreover, the reduction in fetal weight and sizes could also be an attribute of the phytonutrients founds in garlic like flavonoid or that flavonoid could be a potentiating factors against weights increase. The fasting blood glucose level was often significantly lower in the group D (garlic + No pregnancy) when compared to groups B (garlic + pregnancy), A (control) and C (pregnancy, no garlic). This shows that garlic has tendency of reducing fasting blood sugar level and this reducing effect is in line ${ }^{[10]}$. This study has shown that daily feeding of dam with aqueous solution of garlic slightly increases the hemoglobin concentration, packed cell volume and red blood cell counts of group B and D. Group A recorded a slight increase in their red blood cell count and that could be attributed to normal exposure to feed which also resulted in weight gain. This work contradicted the report given by ${ }^{[11]}$ when he reported a reduction in packed cell volume from his own study. According to a research conducted, garlic extract is an active oxygen scavenger. It is thus possible that garlic components compete with haemoglobin on the red blood cell for oxygen resulting in hypoxia which then stimulates haemoglobin synthesis and red blood cell production. It is also possible that the end product of garlic metabolism in the body stimulates the kidney directly to ease formation and secretion of erythropoietin.

White blood cell counts are known to increase sharply when infection occurs as one of the first line of defense of the body The increase in white blood cell counts following the treatment with garlic extract confirms the anti-infection properties of garlic ${ }^{[12]}$. This research is agreement with the earlier work by ${ }^{[13]}$

\section{CONCLUSION}

In conclusion, the results of this study show that AS contain appreciable amounts of some phytonutrients and this provided a basic rationale in its use in the management of some ailments such as hyperglycemia, type 2 diabetes mellitus, hypertension etc. Though antihyperglycaemic effect of garlic has been confirmed in animal studies, scientific evidence from human studies is lacking ${ }^{[14]}$ as most of the clinical studies on antihyperglycemic effect of garlic on fasting blood glucose level in normal healthy individuals but not in hyperglycemic patients, leaving no doubt that the role of garlic in the management of hyperglycemia still needs to be confirmed in humans. Garlic (A. sativium) showed a beneficial effect on weight reduction both on pregnancy and in non-pregnant rats. The effects of garlic in blood parameters were also beneficial to both normal and pregnancy individuals. The increase in white 
blood cell count of both the pregnant and nonpregnant rats showed a beneficial effect in boosting immunity and control of excessive weight gain both by the fetus and the pregnant. Therefore, this study is in agreement with the research work of ${ }^{[14]}$. showed that treatment with garlic extract improves the activation of natural killer cells $\mathrm{T}$ - lymphocytes and also that of ${ }^{[15]}$ who showed that garlic extract stimulates immune functions.

Preliminary investigation on acute toxicity study in mice showed that the extract was not toxic to mice at the tested doses. The probable mechanism underlying garlic hypoglycemic effects is most likely increased insulin secretion and sensitivity [16]. Despite that, antidiabetic potential of garlic has been confirmed in animal studies, while scientific evidence in human studies is lacking ${ }^{[14]}$. Therefore, these results suggest that the consumption of garlic during pregnancy has a beneficial effect in the reduction of maternal/fetal weights and litter sizes and maintenance of the blood parameters including FBGL.

\section{Conflicts of Interests}

The authors have not declared any conflict of interests.

\section{ACKNOWLEDGEMENT}

The authors sincerely acknowledge the efforts of the management and staff of Department of Physiology and Pharmacology of the College of Health Sciences, Benue State University for providing a conducive laboratory and animal house that enabled the conduct of a successful research.

\section{REFERENCES}

1. Nan, L., Enqing, L., G. "Maternal pregnancy body mass index and gestational weight gain on pregnancy outcomes; Plus one 8 (12): e8231 .2013

2. Seiga-Riz A M, Viswanathan M, Moos M $\mathrm{K}$, Deierlein A, Mumford S,Knaack J, Thieda P, Lux L J, Lohr K N.“A system review of outcomes of maternal weight gain according to the institute of Medicine recommendations: birthweight, fetal growth, and postpartum weight retention. American Journal of Obstetrics and Gynecology, 201(4): 3391-3414.2009

3. Graham L E, Brunner H L E, Thompson M E, Ersek J L. Does amount of weight gain during pregnancy modify the association between obesity and cesarean section? Blackwell publishing, 41 (1): 9399. 2014

4. Vellanki, V.S., kocherlakota, V.L., kaul L. " High body mass index in pregnancy, Its effect on maternal and fetal outcome. Journal of Clinical Gynecology and Obstetrics. Elmer press 1(1): 15-18.2012

5. Chung L Y. "The Antioxidant Properties of Garlic Compounds: Allyl Cysteine, Alliin, Allicin, Allyl Disulfide". Journal of Medicinal Food, 9 (2): 205-213.2006

6. Harbone J B. Phytochemical Methods: A Guide to Modern Techniques of Plant Analysis. $1^{\text {st }}$ Edition. Chapman and Hall Ltd., London. pp 49-188. 1973

7. Lorke, D." A new approach to practical acute toxicity testing', Archive of Toxicolology, 54, pp.275-87. 1983

8. OChiogu IS, Uchendu CN, Thedisha JI "A new and simple method of confirmatory defection of mating in Albino Rats" (Rathus Noregicus). Animal Research International. Volume 3(3) 2006 Pp . $527-530$.

9. Mak-Son L, In-Hwan Kin et al (2011) "Reduction of body weight of dietary garlic is Associated with an increase of uncoupling protein mRNA Expression and Activation of AMP - Activated Protein Kinase in Diet induced obesity 1-3. The Journal of Nutrition. Volume 10:10.3945. 2011

10. Rizwan A, Rafeq Alam Kham and Iman Ashraf "Effect of garlic on blood level, and $\mathrm{HbAIc}$ in patients with type 2 diabetes 
mellitus". Journal of Medicine plants

Research volume 5(13). Pp.2922-2928. 2011

11. Harenburg J, Giese C, Zimmermann R. (1998). Effect of dried garlic on blood coagulation, fibrinolysis, platelet aggregation and serum cholesterol levels in patients with hyperlipoproteinemia. Atherosclerosis, 74: 247-249. 1998]

12. Iranloye B O. "Effect of chronic garlic feeding on some hematological parameters ".African Journal of Biomedical Research, 2: 81-82. 2002

13. Tangz Z, Sheng S. Liu, X, Jiank, Suin and Yam M. "Preventive function of garlic on experimental oral parameter and its effect on natural killer cells. Bill. Hum. Medical University. 22:31246-5. 1997

14. Liu CT, Hse H, Cii CK, Chen PS< Sheen LY. "Effect of Garlic oil and diallhytrisuride on glycemic control in diabetic rats". European Journal of Pharmacology 5.6: 165-173. 2005

15. Sumiyoshi H." New Pharmacological activity of garlic and its content (review),Folia Pharm. Japonica. 1997

16. Birdee S G, Yeh G. "Complementary and Alternative Medicine Therapies For Diabetes": A Clinical Review. Clinical Diabetes, 28: 147-155. 2010 